\title{
ANSIEDADE NO MUNDO CONTEMPORÂNEO E SUA INFLUÊNCIA NA EDUCAÇÃO
}

\section{Anxiety in the contemporary world and its influence on education}

\author{
Clarissa de Moraes Guth - Centro Universitário Ritter dos Reis/Brasil \\ Carlos Alberto Veit - Centro Universitário Ritter dos Reis/Brasil
}

\begin{abstract}
RESUMO: O presente artigo busca contribuir com a literatura sobre o tema da ansiedade, considerada na contemporaneidade um sintoma social e, a partir da visão do Humanismo, procura discutir quais seriam suas influências sobre a educação moderna para isso recorreu aos autores de destaque da Abordagem Humanista, como Rollo May e Carl Rogers. Também é sinaizado sobre a Síndrome do Pensamento Acelerado (SPA) que vem acometendo jovens e adultos, sendo facilmente confundidos com outros tipos de diagnósticos aos olhos dos educadores nas escolas. Então se destaca a importância de que as avaliações diagnósticas sejam feitas somente por profissionais capacitados. Concluíse, assim, que as práticas atuais em educação precisam ser revistas para proporcionar um ensino de qualidade, onde a valorização dos educadores faça-se presente em nossa sociedade.
\end{abstract}

Palavras-chave: Ansiedade. Síndrome do Pensamento Acelerado (SPA). Contemporaneidade. Educação. Aprendizagem. Abordagem Humanista.

ABSTRACT: This article seeks to contribute to the literature on the theme of anxiety, considered in contemporary society a social symptom and, from the perspective of Humanism, seeks to discuss what would be its influences on modern education. like Rollo May and Carl Rogers. It is also related to Accelerated Thinking Syndrome (PAS) that has been affecting young people and adults, being easily confused with other types of diagnoses in the eyes of educators in schools. Thus, the importance of diagnostic evaluations being made only by qualified professionals is highlighted. Thus, it is concluded that current practices in education need to be reviewed to provide quality education, where the appreciation of educators is present in our society.

Keywords: Anxiety. Accelerated Thinking Syndrome (SPA). Contemporaneity. Education. Learning. Humanistic approach.

\section{INTRODUÇÃO}

O presente artigo tem por objetivo contribuir com a literatura sobre o tema da ansiedade, considerada na contemporaneidade um sintoma social. Pretende discutir, pelo ponto de vista da Abordagem Humanista, quais seriam suas influências sobre a educação moderna. "Essa abordagem considera a pessoa como um centro de todo o processo contínuo de sua existência, onde ela é livre para direcionar sua própria vida em busca de se atualizar e se desenvolver plenamente" (MOREIRA, 2007, p. 29). 
A partir de autores de destaque do Humanismo, como Rollo May e Carl Rogers, buscar fazer reflexões acerca dos temas discutidos, relacionando-os com questões atuais. “As contribuições de Rogers para a psicologia são notáveis, já que sua teoria da ACP (Abordagem Centrada na Pessoa) enfatiza as relações humanas e visualiza nossa existência como um processo contínuo e não episódico” (MOREIRA, 2007, p. 29).

Já Rollo May, em sua condição de analista das pressões e tensões contemporâneas, questiona conceitos e a origem da ansiedade (MAY, 1977). Sendo assim, o artigo busca, a partir da reflexão, discutir temas contemporâneos relacionados à ansiedade e às questões de ensino-aprendizagem na educação atualmente.

No mundo contemporâneo, deparamo-nos com a imensa rapidez da tecnologia e são inúmeras as facilidades de nos conectarmos com o outro. Além disso, o excesso de informações que recebemos todos os dias faz com que tenhamos dificuldades em assimilar o que é mais preciso. Acabamos por exigir de nós mesmos e dos outros muito mais do que o necessário, causando a Síndrome do Pensamento Acelerado (SPA), que é confundida, muitas vezes, com os transtornos de ansiedade e o déficit de atenção. Assim, todo esse excesso torna-nos pessoas impacientes. Essa impaciência torna-nos reféns da produtividade de todo tipo, torna-nos acelerados, sem tempo para mais nada, sendo que nossos pensamentos também acompanham essa aceleração.

A SPA é "caracterizada pela velocidade de pensamento, diminuição da concentração, e aumento de ansiedade, e compulsão por novos estímulos. Também gera uma hiperatividade funcional, não genética” (MICARONI; CRENITTE; CIASCA, 2010, p.757). Note que a desaceleração constitui uma ferramenta importante em ajudar o ser humano a lidar com ansiedade e a domar a impaciência (SILVA FILHO, 2016). Mas, para tudo isso, precisamos de disposição, de persistir e ter um compromisso profundo com nossa saúde e bem-estar e, acima de tudo, interesse pela vida.

Todas essas dificuldades como ansiedade, impaciência, inquietude, começam a se apresentar no cotidiano dos jovens e crianças de hoje, sob a forma de dificuldades de aprendizagem e interferindo na educação. Nesse aspecto, Cury (2014) afirma: Estudar a Síndrome do Pensamento Acelerado, bem como causas, sintomas, consequências e mecanismos de superação, deveria fazer parte do currículo de todas as escolas, da préescola à pós-graduação. Sendo assim, os alunos poderiam obter um bom rendimento nas

Educação, Psicologia e Interfaces, Volume 3, Número 2, p. 57-68, Maio/Agosto, 2019. 
questões de aprendizagem e os profissionais da educação teriam conhecimento dessa síndrome, podendo exercer de forma favorável sua atuação como educadores.

\section{EDUCAÇÃO E A SÍNDROME DO PENSAMENTO ACELERADO (SPA)}

A ansiedade é um estado psicológico e fisiológico caracterizado por componentes somáticos, emocionais, cognitivos e/ou comportamentais e, às vezes, associada com atividades que demandam habilidades, concentração e autoavaliação (SINICO et al. 2012, apud OLIVEIRA, 2015).

A ansiedade sendo um estado emocional possui componentes psicológicos e também fisiológicos que fazem parte das experiências humanas, levando o organismo ao desempenho (ANDRADE; GORENSTEIN, 1998 apud OLIVEIRA, 2015). Já para outros autores como Fromm e Kierkegaard, a ansiedade é originada dos conflitos da individualidade em desenvolvimento da criança e na necessidade dela de relacionar-se com os iguais (MAY, 1977).

Para Rollo May, “A ansiedade normal, é uma expressão da capacidade do organismo para reagir às ameaças; essa capacidade é inata e possui seu sistema neurofisiológico herdado" (MAY, 1977, p. 209). Quando o autor refere-se ao que é herdado, ele quer dizer que a herança da ansiedade ou medo possui um pressuposto necessário, que seria a capacidade do organismo humano reagir às ameaças, e isso os nossos ancestrais também possuíam.

Alguns autores da Teoria da Aprendizagem pensam que a aprendizagem tem o seu papel estabelecido na ansiedade, uma vez que os eventos que terão valor de ameaça para um indivíduo vão depender necessariamente do que ele aprendeu anteriormente. Contudo, este autor parece não concordar com essa afirmação, pois ele sugere que a capacidade para a ansiedade não seria aprendida, mas sim as quantidades e formas dela em um dado organismo é que seriam aprendidas.

"Isso significa que a ansiedade normal é uma função do organismo como organismo; todo o ser humano experimentará ansiedade em situações de ameaça aos seus valores vitais" (MAY, 1977, p. 211). Sendo assim, ele ressalta que a aprendizagem colabora para a questão da ansiedade. Seria o que é considerado uma situação de ameaça a valores vitais, para cada indivíduo, dependendo então do que foi aprendido pelo mesmo.

Porém, quando esta ansiedade é excessiva, os indivíduos paralisam-se diante de seus problemas e acabam por empobrecer as características boas de suas personalidades 
e assim acabam que por evitar confrontar seus conflitos. Nas próprias palavras de Rollo May, sobre acomodar-se frente ao sintoma chamado ansiedade, ele coloca:

ao aceitar o empobrecimento da personalidade, uma pessoa pode, sem dúvida, comprar uma liberdade temporária da ansiedade. mas o preço para essa "transação" é a perda das características únicas e sumamente preciosas do eu humano (MAY, 1977, p. 352).

A ansiedade sempre esteve presente no comportamento dos seres humanos desde tempos mais primitivos, uma vez que ela é a que constitui a natureza humana a partir de sentimentos de ameaça, perigo, do que ainda não é conhecido (NASCIMENTO; CALSA, 2015). Sabendo disso, podemos afirmar que muitas vezes a ansiedade, até mesmo de situações ocorridas dentro do próprio ambiente familiar, pode provocar ou colaborar para um baixo rendimento na escola, tanto em questões da aprendizagem como também relacionadas à sociabilidade com os grupos de iguais.

Weiss (2010) destaca que situações mal conduzidas na escola podem gerar e até exacerbar a condição de ansiedade dos estudantes, uma vez que toda aprendizagem é acompanhada de certo nível desta emoção (NASCIMENTO; CALSA, 2015). Algumas teorias da psicanálise discutem a questão de uma ansiedade primitiva que, com o passar do tempo, a criança vai se desenvolvendo. Essa ansiedade típica dos anos iniciais vai se modificando, quando a criança vai adquirindo habilidades como as físicas, adquirindo a linguagem e progredindo em seu desenvolvimento intelectual, quase sempre em atividades que envolvem o lúdico no contexto das escolas (NASCIMENTO; CALSA, 2015).

Existem momentos em que certa tensão interna, talvez até provinda de conflitos do campo familiar, como a separação dos pais, negligência ou questão de doença de algum dos pais, possa estar colaborando para uma ansiedade descontrolada.

A ansiedade, assim como afirmado por Freud está ligada a uma forma de sofrimento psíquico ocorrendo em função de um conflito interno, podendo ser desencadeada por momentos de tensão, onde o indivíduo possui uma condição pré-existente (THEISEN, 2015 p. 39).

Por exemplo: quando o rendimento do aluno fica reduzido e o impede de fazer uma apresentação de trabalho ou de realizar uma prova na escola. 
Tudo isso pode ser a realidade de muitos alunos nas escolas e que não por diversas vezes professores tomam-nos como "alunos-problema" de suas classes ou encaminhandoos para diagnósticos que não foram bem conduzidos. Vários estudos (MARGIS et al. 2003; LOCH, 2009; WEISS, 2010) indicam que a ansiedade pode ser considerada normal quando sua ocorrência é pontual, como em um dia de prova, uma apresentação de trabalho ou entrevista de emprego (NASCIMENTO; CALSA, 2015).

Quando, porém, essas situações encontram-se com uma intensidade e de forma constante, fazendo com que os indivíduos sintam-se incomodados ou outros ao redor deles comecem a perceber suas dificuldades, essa respectiva ansiedade aparentemente normal pode tornar-se alvo de preocupações. A ansiedade excessiva pode levar o aluno a acreditar que está sendo atacado ou perseguido pelo professor, ou até mesmo pela disciplina em que ele sente dificuldades, ou ainda, sentir que desaprendeu o que já sabe e no qual pode sentir-se seguro quando aprende algo novo (NASCIMENTO; CALSA, 2015).

Por isso que autoras como Nascimento e Calsa (2015) colocam que atualmente a ansiedade patológica vem afetando adultos, jovens e crianças. Vemos essa questão nas salas de aula confundindo-se com outros diagnósticos aos olhares de nossos educadores pela falta de informação. Constata-se que a criança pequena e o pré-adolescente possuem menos capacidade para se concentrarem ou terem foco em uma atividade por muito tempo, diferentemente dos adultos; porém, não é critério de classificação para a hiperatividade (MAIA; CONFORTIN, 2015).

Autores destacam que os avanços tecnológicos em conjunto com fatores da pósmodernidade como pressões sociais, políticas e econômicas contribuem para aumentar problemas emocionais (ARAÚJO; MELO; LEITE, 2006 apud NASCIMENTO; CALSA, 2015). Os educadores convivem com estudantes que possuem hiperatividade; porém, não sabem como lidar com isso em sala de aula e acabam confundindo o mau comportamento de seus alunos, prejudicando significativamente o processo aprendizagem dos mesmos (MAIA; CONFORTIN, 2015).

Para evitar diagnósticos imprecisos e a patologização em excesso das dificuldades encontradas nos alunos, autores sugerem que a avaliação seja realizada somente por profissionais especializados, como médicos ou psicólogos, quando suspeitos pela instituição escolar (ARAÚJO; MELO; LEITE, 2006 apud NASCIMENTO; CALSA, 2015). 
Crianças da contemporaneidade, porém, estão sob pressão, pois são atingidas por exigências cada vez maiores de serem sanadas tanto pela família quanto pelas escolas e pela sociedade. Nas próprias palavras do autor que escreve sobre o tema:

[...] a sociedade atual é muito dispersiva! Há uma hiperestimulação, que tem suas vantagens obviamente, mas é uma sociedade que comprimiu o tempo, alargou o espaço, e tem muitas possibilidades. As crianças ricas hoje tem muitas escolhas, e acabam sem ninguém, ficam sozinhas! É como um restaurante self-service, em que você se perde, acaba ficando com aquele prato enorme, quer experimentar de tudo! Assim em minha opinião, o TDAH, bem como a ansiedade, é o espelho de uma sociedade que ainda não aprendeu a gerir as coisas que ela mesma criou (MACEDO, 2013, p. 13 apud NASCIMENTO; CALSA, 2015).

Atualmente, com as inovações tecnológicas e as redes sociais, que nos conectam com total facilidade a toda hora, saturam-nos de inúmeras informações. Entretanto, há mais de décadas observa-se que o ritmo frenético no qual as pessoas vivem tem afetado seu cotidiano nesse mundo moderno (SILVA FILHO, 2016). Silva Filho (2016) diz que as pessoas vivem cada vez mais sobrecarregadas de informações oferecidas aos sentidos das mais variadas formas, além de terem pensamento acelerado, resultando em ansiedade. Isso dificulta o nosso processo de selecionar as mais convenientes informações e acaba por transformar os indivíduos em verdadeiras máquinas pensantes e com falta de concentração.

A falta de concentração é devida a uma síndrome que se desenvolveu em razão do sistema social, assim é possível pensar na possibilidade de nossos alunos também ter a SPA, o que prejudica a assimilação das informações, a organização e a capacidade de resgate delas, comprometendo o desempenho do raciocínio (CURY 2014, p. 102 apud DORIGNON; OLIVEIRA, 2015).

Esse fenômeno pode atingir tanto adultos quanto jovens e crianças e acaba dificultando na hora de diferenciar o principal sintoma que pode estar causando um baixo rendimento no trabalho e no aprendizado escolar. A Síndrome do Pensamento Acelerado (SPA) faz com que a mente carregue-se de muitas preocupações exageradas em um longo período de tempo, fazendo com que o indivíduo não consiga manter o foco em um único objetivo, por isso pode-se confundir com o Déficit de Atenção e a Hiperatividade.

A Síndrome do Pensamento Acelerado (SPA) segundo Cury (2014) apresenta-se como um processo que produz uma grande construção de pensamentos em uma alta velocidade, que acaba por levar o cérebro à exaustão, resultante do excesso de estímulos

Educação, Psicologia e Interfaces, Volume 3, Número 2, p. 57-68, Maio/Agosto, 2019. 
e atividades. Esse grande esforço contínuo pode causar uma série de sintomas como: ansiedade excessiva, irritabilidade, inquietação, déficit de concentração, esquecimentos e fadiga excessiva. O que podemos observar no comportamento dos jovens de hoje, como quando passam muito tempo conectados em seus aparelhos de celular e com suas televisões ligadas, fazendo ao mesmo tempo suas atividades escolares, é uma sobrecarga de estímulos para sua função mental chamada atenção.

Esse hábito comportamental dos jovens de hoje reflete no aprendizado e nas escolas, pois precisam cada vez mais de estímulos ou de novos estímulos para estimular sua atenção, quase como um vício. Quando estão em sala de aula, se o conteúdo não é reconhecido como interessante, o desinteresse é rapidamente expresso pela atenção desviada para o celular ou para as conversas. Acaba-se a bateria do celular, se não tem como carregá-lo em seguida, ficam entediados, irritadiços e inquietos.

Silva Filho (2016) afirma a existência de dois traços comportamentais nos jovens de hoje que certamente compõem a Síndrome do Pensamento Acelerado (SPA), eles são: a inquietude e a agitação. Além disso, os que trabalham com a questão da educação muitas vezes não estão preparados para lidar com esses traços comportamentais citados, o que se torna uma dificuldade no ensino e um desafio para a educação contemporânea. "Eles, os educadores, têm conhecimento da área e disciplinas deles. Mas, é preciso saber como educar a emoção" (SILVA FILHO, 2016). Com isso, percebemos que é preciso uma educação que desenvolva meios para trabalhar com a emoção, que consiga de alguma forma desacelerar a atenção, para que a mesma não seja dissipada do objetivo final que precisa ser atingido em sala de aula. Precisamos de alunos, de jovens com capacidade de controlarem suas frustrações, falar delas, que consigam emergir sua atenção com persistência, para não perder o foco; contudo, precisamos de uma juventude com mais perseverança.

\section{EDUCAÇÃO E ANSIEDADE}

... Só de fato por milagre é que os modernos métodos de ensino ainda não liquidaram inteiramente a sagrada curiosidade da pesquisa; pois essa delicada plantazinha, além de certa estimulação, necessita, sobretudo, de liberdade; sem esta, estiola-se e morre fatalmente (EINSTEIN apud ROGERS, 1978, p.7).

A educação não é um objetivo, mas um processo, o qual é construída ao longo da existência da pessoa (SILVA FILHO, 2016). O que se tem observado é que muitas 
crianças e jovens estão desinteressados. Muitos chegam a reclamar das aulas que frequentam, alegando serem entediantes. Isso acontece não somente no ensino fundamental ou médio, mas principalmente nas universidades.

Esse acontecimento é típico dos tempos atuais; são efeitos da pós-modernidade, onde o educador deve se desgastar para atrair a atenção e o interesse de todos os seus alunos; porém, sabemos que não é uma tarefa fácil. Rogers (1978) traz dois significados da aprendizagem: aquela que é de uma forma imposta aos alunos, onde somente a memória faz a vez e não se traduz em termos de sentido e de sentimentos; e aquela na qual faz totalmente sentido, torna-se aos poucos existencial.

A aprendizagem existencial é aquela que possui um significado e é repleta de pleno sentido e de alguma forma de liberdade. O indivíduo vivencia-a como importante e precisa e guarda-a consigo, pois aquilo que vivenciou dotou-se de sentido. "Tal aprendizagem tem ela a qualidade de um envolvimento pessoal a pessoa, como um todo, tanto sob o aspecto sensível quanto sob o aspecto cognitivo, inclui-se no fato da aprendizagem" (ROGERS, 1978, p. 21). Ele afirma que, quando se possui um currículo pré-estabelecido, deveres iguais para todos e uma única metodologia, limita-se a liberdade para aprender e para escolher e somente se reproduz. Nossa educação atualmente resume-se assim: os alunos perdem o interesse, a curiosidade e o encanto de aprender e nossos educadores perdem o de ensinar.

Alguns costumam dizer que, na realidade, esta dificuldade atual da educação pode ser sanada pela questão de introduzir o novo, ou seja, trazer a tecnologia para as salas de aula. Outros não concordam com essa hipótese porque a educação é um processo que tem que ser construído desde o início e requer treinamento, interesse, atenção e, principalmente, dedicação. Introduzir a tecnologia para as aulas seria bom no sentido de auxiliar nas tarefas, por conta da facilidade e praticidade de assistir um vídeo, baixar materiais ou trazer algo interativo. A tecnologia ajuda, mas ela é nada mais do que uma ferramenta que auxilia na construção do conhecimento e da educação (SILVA FILHO, 2016).

"A nossa educação enfrenta, hoje, inacabáveis desafios, diferentes e muito mais sérios do que quantos já se lhe apresentaram durante a sua longa história" (ROGERS, 1978 p. 12). Rogers escreveu isso em seu livro: "Liberdade para Aprender", em 1969, e ainda hoje vemos que, ao invés de mudanças ou respostas para antigas questões, 
continuamos a dar voltas em círculos. Podemos dizer que encontramos mais problemas do que antigamente. "Nosso moderno sistema educacional parece para muitos de nós completamente impossível de dar liberdade de aprender aos estudantes, pois existem muitos limites exteriormente impostos" (ROGERS, 1978, p. 43).

Mas o que deveria importar é o conseguir dar liberdade aos alunos dentro desses limites que são impostos. Permitir a liberdade de escolha é garantir a autonomia eficaz dos alunos.

Acabaria formando assim um contexto favorável de ensino, que se resumiria em uma aprendizagem internalizada que fosse fazer parte da existência de cada um e não apenas um conjunto de conteúdos jogados ao aluno, onde o próprio somente os decore para uma prova (ROGERS, 1978, p. 84). Uma aprendizagem para a existência do aluno seria aquela que fizesse sentido ao mesmo que, ao se colocar de certo modo na prática, como um todo, já proporcionasse ferramentas para lidar com suas dificuldades. O que vemos, porém, desde muito na pós-modernidade, é a desvalorização do ensino refletida nas faltas de recursos e de infraestrutura necessária. Às vezes na falta de professores ou até mesmo na falta de salários adequados a estes, o que acaba por proporcionar uma educação de péssima qualidade e deficitária.

Voltando à questão da ansiedade e relacionando com a educação, o aluno pode encontrar dificuldades na hora de realizar uma prova. Quando a ansiedade faz-se presente, pode prejudicar o rendimento do aluno e não é difícil ouvirmos de alguns que sua dificuldade é a matemática, por exemplo. Diante disso, alguns fatores são considerados como causa para a "não aprendizagem" da matemática, como: a ineficiência da metodologia pedagógica, uma psicopatologia como a ansiedade só que ligada à questão dos números (OLIVEIRA, 2015).

A ansiedade na escola é ocasionada tanto por fatores internos, como, por exemplo, a preocupação com o desempenho próprio, ou externos, no caso de elevar o desempenho pela exigência dos pais. A ansiedade nos jovens, atualmente, pode estar relacionada com a questão da cobrança dos pais e dos educadores na escola, e também com a questão de ameaças desconhecidas em situações sociais, podendo estar menos associada com a separação dos pais e os danos físicos (MIGUEL, GENTIL; GATTAZ, 2011 apud OLIVEIRA, 2015).

É observado por vários autores o fato de a dificuldade na disciplina matemática estar associada à metodologia desenvolvida pelo professor (OLIVEIRA, 2015). Essa 
dificuldade, segundo a abordagem humanista, poderia ser diminuída com a introdução de um ingrediente importante, que seria a confiança e a empatia partindo do próprio professor como um facilitador do processo de aprendizagem (ROGERS, 1978).

De acordo com Rogers, o professor continua sendo o astro central na constelação da escola. O que teve mudança, segundo o autor, foi a metodologia e as técnicas (ROGERS, 1987). "Estas últimas (as pedagogias novas) insistem, sobretudo, nos métodos pedagógicos como instrumentos de formação" (PAGÉS, 1965 apud ROGERS, 1987 p. 131). Ou seja, observando a educação atual encontramos os mesmos desafios, só que hoje temos o auxílio da tecnologia avançada que, de uma forma ou outra, se não utilizada com consciência também acaba por atrapalhar as práticas educacionais.

\section{CONSIDERAÇÕES FINAIS}

Partindo das seguintes interrogações "Pode a educação preparar indivíduos e grupos para viverem confortavelmente num mundo em que a mais acelerada transformação é o tema dominante? Ou essa é uma acomodação que escapa ao poder humano? Ou ainda, é impossível à educação realizar um objetivo tão estranho ao seu passado?"

Essas interrogações não são de hoje. Carl Rogers (1987, p. 12) as fez em seu livro Liberdade para Aprender, de 1969; porém, elas continuam vivas com o passar dos anos. A contemporaneidade, com a introdução das informações, transformou aspectos nos indivíduos de hoje. As pessoas não se reúnem mais com tanta frequência para conversarem; ao invés, utilizam as redes sociais para isso, ou seja, até os contatos humanos estão em constante mudança. As pessoas vivem atarefadas de compromissos que vão aceitando em seu cotidiano sem nem mesmo se dar conta de que não terão tempo com suas famílias.

Quando encontram este tempo, não sabem por que não conseguem aproveitar tanto quanto deveriam, ou seja, seus pensamentos não estão no presente vivendo o agora, experimentando oportunidades. Essas pessoas encontram-se longe em seus pensamentos cheios de preocupações futuras que ainda nem sequer aconteceram, acabando por tornarem-se aceleradas, ansiosas e sem tempo para si.

Com isso, devem-se mudar inclusive cada vez mais as práticas em educação, pois isso se reflete nos alunos que chegam às escolas. Eles também se encontram em sua

Educação, Psicologia e Interfaces, Volume 3, Número 2, p. 57-68, Maio/Agosto, 2019. 
maioria ansiosos e inquietos. Vemos, porém, esse processo andando lentamente, o que torna os alunos de hoje desinteressados naquilo que poderia ser a mudança futura, o ensino.

Paulo Freire (1983), ao afirmar que as ideias importadas devem ser "reduzidas sociologiacamente, ou seja, estudadas e integradas em um contexto nativo; devem ser criadas e adaptadas; neste caso, a importação é reinventada ou recriada" (FREIRE, 1983 apud VIRGINIA MOREIRA, 2007, p. 32). Adaptar conteúdos ou métodos estrangeiros para a nossa nação é importante e não apenas utilizarmos da mesma forma que já são utilizados, pois o conteúdo perde o valor, perdendo também seu sentido, que passa a ser apenas reproduzido e decorado. Não sendo aprendido por seu significado e não fazendo sentido para o aluno, em relação ao que vê em seu cotidiano, ele não o internaliza, não o aprende de verdade.

Nisso vemos também professores desinteressados pelo que escolheram exercer como carreira, pois não são valorizados pela sociedade atual. Isso se torna um descaso com a educação em geral. E essas perguntas que Rogers fez na década de 1960 foram respondidas por ele com a seguinte frase: "Não sei". E a pergunta trazida à contemporaneidade é: será que atualmente conseguiríamos encontrar respostas para estas mesmas seguintes perguntas ou continuaremos a repetir também o "Não sabemos"?

\section{REFERÊNCIAS}

CURY, Augusto. A ansiedade [recurso eletrônico]: como superar o mal do século: a síndrome do pensamento acelerado: como e por que a humanidade adoeceu coletivamente, das crianças aos idosos. São Paulo: Saraiva, 2014.

OLIVEIRA, Angelita. Ansiedade à matemática em alunos do $6^{\circ}$ ao $^{\circ}$ ano do ensino fundamental no colégio estadual Jardim Tiradentes: um estudo comparativo. Educação e cultura em debate, v.1, n.1, 2016.

MAIA, Maria. I. R; CONFORTIN, Helena. TDAH e Aprendizagem: um desafio para a educação. PERSPECTIVA, Erechim. v. 39, n.148, p. 73-84, dezembro/2015.

MAY, Rollo. O Significado de Ansiedade: as causas da integração e desintegração da personalidade. Rio de Janeiro: Zahar Editores. 1977.

MICARONI, Natália Inhauser Rótoli; CRENITTE, Patrícia Abreu Pinheiro; CIASCA, Sylvia Maria. A prática docente frente à desatenção dos alunos no Ensino Fundamental. Rev. CEFAC, São Paulo, v. 12, n. 5, p. 756-765, Out. 2010. Disponível em: <http://www.scielo.br/scielo.php?script=sci_arttext\&pid=S1516$18462010000500006 \& \operatorname{lng}=$ en\&nrm=iso $>$. Acesso em 04 Jan. 2019. . http://dx.doi.org/10.1590/S1516-18462010005000101. 
MOREIRA, Virginia. De Carl Rogers a Merleau-Ponty: a pessoa mundana em psicoterapia. São Paulo: Annablume, 2007.

NASCIMENTO, Mariana. do N. C; CALSA, Geiva. C. Como aprendem os alunos ansiosos? A descentração e a tomada de consciência como prática pedagógica de professores. Schéme -Revista Eletrônica de Psicologia e Epistemologia Genéticas, v. 7, n.2, p.98-120, 2016.

ROGERS, Carl. Cresça e Faça Crescer. 5.ed. Canoas: La Salle, 1987.

ROGERS, Carl. Liberdade para Aprender. 4.ed. Belo Horizonte: Interlivros, 1978.

SILVA FILHO, Antonio. M. Ansiedade e impaciência: cânceres sociais na Educação e Relações Humanas. Revista Espaço Acadêmico, Pernambuco.v. 15, n. 177, 2016.

THEISEN, Cristiane. Ansiedade: sintoma social contemporâneo, 2016.

\section{Credenciais da/os autora/es}

GUTH, Clarissa de Moraes. Centro Universitário Ritter dos Reis/Brasil.

VEIT, Carlos Alberto. Centro Universitário Ritter dos Reis/Brasil.

Endereço para correspondência: Clarissa de Moraes Guth. E-mail:

clarissapsicologaclinica@hotmail.com

Como citar este artigo (Formato ABNT): GUTH, Clarissa de Moraes; VEIT, Carlos Alberto. Ansiedade no mundo contemporâneo e sua influência na educação. Educação, Psicologia e Interfaces, v. 3, n.2, p. 57-68, 2019. DOI: https://doi.org/10.37444/issn2594-5343.v3i2.139

Recebido: 04/03/2019.

Aceito: 20/6/2019. 